\title{
Nikos Kazantzakis's phenomenology and its relevance to the study of organizations
}

\author{
Stephanos Avakian Business School, University of Brighton Business School, Brighton, UK
}

\begin{abstract}
This paper examines Morgan's theorization of images of organizations from a phenomenological perspective using the works of Nikos Kazantzakis. The paper argues that Morgan's representation of metaphors currently favours an entitative interpretation of influence and control, undermining novel processes deeply embedded within existential nuances situated in the realm of the human experience. By focusing on Kazantzakis's phenomenology, the paper proposes that a theorization of transitionality demonstrates that a content-process struggle is rooted within a permanence-temporality struggle constantly conditioned against individuals' transitoriness of existence. Relatedness, affirmation and temporality represent three interdependent process states and each exposes self-existential tensions that regulate the directionality of one's transitions. Such transitions are thought to challenge the entitative form with which organizations are portrayed in the individual. The paper shows that a conceptualization of transitionality through Kazantzakis provides a new scope for understanding the structure of movements situated in the self and for customizing the forces of permanence and temporality.
\end{abstract}

\section{Introduction}

This paper examines the creative use of metaphors found within Morgan's conceptual work (1980, 1983, 1986, 1996). In presenting a diverse range of metaphors, Morgan (1980, 1983, 1986) identifies that images can be conceptualized as capable entities. They condition how human consciousness can become an extension of either conscious and/or unconscious motifs. For Morgan the organization is viewed as a social entity that can create attachment, commitment, recognition and acceptance. It is an entity that possesses an identity of its own and can regulate human behaviour. In discussing the power of the images, Morgan (1986, 1996) argues for the rising importance of symbolism as a dominating factor that carries a catalytic effect. Hence, managers can be inspired by images of progress to create an ongoing impulse towards growth and development whilst seeking to stimulate interest and invite commitment from others (Nicotera 2013). This paper chooses to focus on the conceptual limitations of Morgan's metaphors accounting for 'process' and 'content' relationships situated in the experience of transitionality. Hence, it advances earlier conceptualizations on process theory by using Nikos Kazantzakis's process philosophy. By developing a process typology the paper proposes that the accommodation of organizational processes, as identified within the nuances of human experiences, requires a great exposition of the human existential struggle between 'entities' and 'processes'. I argue that the presentation of a theoretical framework that can enable the study of human reactions requires the deployment of a phenomenological perspective that can account for the nuances of existence itself. Provided that the metaphors by which organizations are portrayed can change in light of changing human conditions, there is a need to account for the timely transience of this development. The research question I seek to address therefore is how can a Kazantzakian process philosophy respond to an entitative understanding of organizations as metaphors and advance nuances concerning the experience of human existence? By drawing insights from the literary works of Nikos Kazantzakis (Kazantzakis 1952, 1960a, 1960b, 1979; Kazantzaki 
1968), the paper proposes that a struggle between content and process remains part of a greater and existential struggle rooted between permanence and temporality. The need to bring forth into existence underpins a greater existential desire to use methods of production to achieve permanence and continuity. However, such permanence is continuously challenged in the course of one's life transitions and generates repetitive voids of meaning that contribute to frustration and desperation (Middleton 1994, 2005, 2007). In translating Kazantzakis's works my typology is based on three phenomenological states of existence, namely (a) relatedness, (b) affirmation and (c) temporality. The contribution of this typology advances earlier insights on process theory that demonstrate the instrumental role of the individual in making self-centred transitions that accommodate but also simultaneously challenge accounts of permanence and continuity. These transitions emerge from a human existential struggle but extend into organizational life in terms of work processes being identified and performed by members (Tsoukas and Chia 2002). I propose that a theorization of self-led transitions cannot be substituted by a presentation of metaphors, as was previously thought. Kazantzakis's analysis shows that all entities are experienced as highly fragmented and their control is continuously self-regulated by the appropriation of existential transitions of permanence and temporality.

The paper is divided into three parts. The first part focuses on Morgan's (1986) metaphors, examining how metaphors enable the development of comparative associations that lead to new insights about the order by which processes are organized. Morgan's $(1980,1983,1986)$ reference to organizations as instruments of domination, brains, systems, machines etc. suggests that metaphors carry the capacity to be an alternative analytical exposition that situates the parts and the whole within a common frame of analysis. The creation of associations with and within images carries an explanatory function (Sid 2002). Images expose an autopoietic system of self-production and self-continuation (Morgan 1980). Ultimately, the function of an image is rooted in the organizing logic that makes up the core operations of the system that sustains it over time. Hence, a study on images accelerates the methods for making observations as an outcome and for producing different associations about the image and from different angles (Kostera 2012; Shepherd and Sutcliffe 2015).

The second section of the paper finds that the interpretation of the metaphors is situated within a series of entitative attributes that undermine the development of human-related processes that interact with the entitative aspects of the organization. For example, organizations are considered instruments of domination, because of their power to control human behaviour, and as psychic prisons, because of their capacity to influence the perceived boundaries with the intention of fostering employee compliance. A current limitation that requires further development in the literature is the study of human reactions (Demir and Lychnell 2015), as these are triggered by the entitative power of the organizations' confinement. A conceptualization of metaphors needs to account for entitative but also process-like qualities (Weick 1979; Weick and Sutcliffe 2001; Weick 2003). However, such an investigation needs to account for greater nuances behind the flow of human experiences (Reissner, Pagan, and Smith 2011), which can explain the interpretation of tensions that develop from the human accommodation of content and process properties. 
The third section of the paper introduces the work of Nikos Kazantzakis, focusing on the development of his phenomenological exposition, where the struggle between content and process is rooted within a much broader existential struggle between permanence and temporality. This section introduces a typology of three transient relationships that are identified as states of existence. It suggests that a conceptualization of transitionality advances a range of previous phenomenological motifs regarding the individual self and to accommodate existential tensions. These tensions are made evident through a wider conceptualization between permanence and temporality (Bien 2007a; Middleton 1998, 1994). A conceptualization of transitionality captures, metaphorically speaking, different stations in the course of the development of one's life. Hence, the need for permanence comes into conflict with the reality of temporality. I argue that a phenomenological exposition through Kazantzakis identifies a greater set of structures that mobilize and organize tensions between content and process ultimately rooted in the struggle between permanence and temporality. Furthermore, Kazantzakis identifies that transitions are regulated through interpretive accounts of existence that are selfcentred (Middleton 1994, 1998). This view proposes that an accommodation of organizations as images needs to identify with the transitoriness of human existence within the different pinnacles of its development.

\section{Images of Organizations}

Morgan's $(1980,1983,1986,1993)$ deployment of metaphors assists with furthering theorization on organizations as systems of production, instruments of domination, psychic prisons, natural organisms etc. (Schoeneborn, Vásquez, and Cornerlissen 2016). Metaphors comprise conceptual schemata and carry an autonomous function contributing to the development of self-explanatory accounts that emerge from the primary function of the metaphors (Putnam and Boys 2006; Kostera 2012). For example, Morgan's (1986) reference to organizations as machines advances prior understandings of the power of automation and repetitiveness. A machine has clear and definable structures and its control lies outside its design. Its organized order is championed through an exercise of rational logic and different forms of causal relationships (Orlikowski 2007). However, the perceived and practical added value of its behaviour is found in the premise that it is measurable and predictable. An experience of organizing through a machine metaphor can be defined by the segmentation of tasks and by producing controllable and measurable outputs (Baritz 2005). However, the power of the machine or similar images is found not only in the description of the metaphor itself (Morgan 1983, 1986, 1996) but also in its capacity to be used as a medium from which to produce insights through the making of new/different comparisons. Following the robust integration of machines within our society, it is accepted that their heightening significance demonstrates that they have generated an important outcome by simplifying prior and complex operations through repetition (Orlikowski 2007). Machines constitute an indispensable element of society whose absence can generate greater harm than good. This is because a system of transactions has already been built on a web of interdependent relationships that happen to maintain order and sustain prior functions (Orlikowski 2007). Prior operations cannot be replaced through non-technological means. Hence, machines created new constraints in terms of how human judgements and expectations on productivity and efficiency are created. Methods of human intervention continue to evolve with new advancements in automation. The advancement of robotics exerts a more self-autonomous and domineering pressure than ever before seen in the history of humanity. Hence, the 
attributes of a metaphor are found in the detection of repetitive behaviour patterns that carry a teleological scope (Kostera 2012; Schoeneborn, Vásquez, and Cornerlissen 2016). However, the conceptual usefulness of the metaphors is found in their capacity to reveal new/different interdependent qualities hidden from view (Searle 1979; Boje 1991, 2001, 2014; Shepherd and Sutcliffe 2015). Organizations' members might not realize the insensitivity in which they operate unless such an analogy is created (Morris and Feldman 1996). Hence, the metaphors' self-imaginative power is found in deciphering a new synthesis between cognitive and emotional forms of representation that would be difficult to obtain otherwise (Weick 2011). Furthermore, a metaphor becomes a meaningful construct because it carries different layers of understanding that cannot be easily obtained solely from the study of a phenomenon (Schatzki 2005; Smith 2001). Thus, it is suggested that metaphors create a mirroring effect, enhancing the quality of human reflexivity and used to obtain reliable information from within (Morgan 1983, 1986, 1989; Strati 1997). For example, the position that the organization is a systems of control (Morgan 1986) assumes that there is a defined presence of tangible and intangible boundaries that literally and/or symbolically control access. A system operates within reciprocal relationships that define and redefine roles and relationships between parts and their connections to the whole. In a similar way, members are several and separate entities that work in isolation from each other yet remain part of the same organizing body. Organizations' members contribute to the organization as an entity that exists separate to themselves (Shepherd and Sutcliffe 2015; Schoeneborn, Vásquez, and Cornerlissen 2016). This metaphor suggests that an understanding of the organization is advanced through a study of natural organisms or machines. Despite the conceptual novelty of Morgan's metaphors, still little is known about the conceptualization of the metaphors' content and process properties situated within the different categories of the human experience. Berger and Luckmann (1966) initiated a discussion of different processes in which images are internalized. Their categorization includes (a) objectification, (b) internalization and (c) externalization. Through these typologies they suggest that the embeddedness of social reality is conditioned within a series of recursive and transformative stages that occur at different points in the course of the human experience. This view was also advanced by Weick (1995) through his concept of reification. Reification suggests that people exert a participatory role in enacting that which might be considered merely ambiguous and imaginary. Enactment enables a stabilization of the ambiguous properties that might be associated with an action or desire. For Weick (1995), this human action reinforces the presence of the seeming ambiguous act and contributes to the process of organizing. Despite the contributions made in the literature, still little is known about the relationship between the organizing principles that regulate the abovementioned transitions within the human experience. Hence, the research question this paper seeks to examine is how can a Kazantzakian process philosophy respond to an entitative understanding of organizations as metaphors and advance nuances concerning the experience of human existence? A study of a process perspective remains valuable for understanding how perceptions of position and/or confinement are regulated via members' experiences (Hernes and Maitlis 2010; Langley et al. 2013). Following research on the phenomenology of organizations (Holt and Sandberg 2011), it is suggested that unearthing processual motifs is still a scantly researched phenomenon for understanding the design of human processes. For example, one's position within a specific metaphor cannot suggest that the individual has the exact same experience within the place of another metaphor. The variation of the members' experiences is dependent 
on the members' engagement with tangible events and with their own repertoire of interpretations developed on the basis of these events (Searle 1979; Morgan 1986). However, a description of the metaphor is important for determining the human reactions that emerge from it. Morgan's (1986) metaphors attempt to integrate many broad theoretical positions. These are founded within different disciplines and include theories from sociology, psychology, natural science, organization studies etc. However, the emergence of process studies (Langley et al. 2013) shows that the study of the individual is not clearly understood for how entitative and process structures are organized. For example, a study of when and how images are internalized within the different stages of the human experience requires further examination to understand the timely development of the events themselves and their impact on members' experiences (Oswick, Keenoy, and Grant 2002; Höpfl 2005). Images can be internalized within the experiences of organizations' members so that the representation of the metaphors remains inadequate for understanding the unfolding relationship between the entity and process relationships (Demir and Lychnell 2015). A generalization of the function of the metaphor mechanism is associated with the human reaction that responds to the stimuli of that particular metaphor. For example, the achievement of a task remains a profound event for an organizational member (Koerner 2014). The experience of success can be internalized as an achievement of one's potential success and even career progression (Hochschild 1997, 2003). An individual can develop a strong and/or weak association with the organization such that she/he can generate strong emotions that favour/resist management decisions. However, the internalization of success is not a stable process on its own but can change over time depending on other stimuli and reactions. For example, the possibility of one member challenging the perceived accomplishment of another can demoralize the latter (Michel 2014). Hence, the organizational members' support or resistance is dependent on how events are internalized within the arena of the members' own experiences and these experiences transition over time (Morris and Feldman 1996; Langley et al. 2013). Studies on well-being (Brook 2013) and emotional labour (Hochschild 2012) indicate that members go through different stages of identifying and transforming the significance of outer events within their own anticipations. Such a process enables them to conform to a challenge or to a desired outcome. The individual self remains an anthropomorphic autonomous schema of cognition, logic and emotion. It can reciprocate inputs and outputs as representing already-self-defined activities. This view has recently been advanced in the literature through a growing research interest in emotional labour (Hochschild 1983, 1997, 2003, 2012) and mindfulness (Kudesia forthcoming), where the accommodation of organizational pressure carries repercussions for one's sense of well-being. The expectations of management can be overwhelming for employees, who may suppress their own feelings (Morris and Feldman 1996). However, studies in this literature carry a growing attention on the role of the individual in managing her/ his quality of life against the expectations of the organization. This view suggests that members move through different spectrums of consideration when it comes to conditioning and compliance. The decision to support and/or resist a course of managerial decisions is rooted in the belief that it can affect the well-being of the people involved. It is suggested that the exercise of human reflexivity can become a catalyst for understanding incidents of emotional attachment and detachment, but also for generating the capacity to manage conflict in the midst of power struggles (Czarniawska 1998).

\section{Nikos Kazantzakis and organization studies}


Few novelists attract as much global attention as Nikos Kazantzakis (Bien and Middleton 1996). The Greek novelist was feted for his ability to articulate complex meanings through storytelling (Middleton 2007, 2010). Following his studies with Henri Bergson (1859-1941) and his doctorate on Friedrich Nietzsche (1844-1900), Kazantzakis (1883-1957) did not follow a conventional academic career that could assure him of immediate financial gains (Middleton 1994, 1998, 2000, 2005, 2007, 2010). Instead, he dedicated his life producing novels and translating works between German, French and Greek. Kazantzakis captured important philosophical truths and translated complex ideological problems into simple propositions made accessible to the common reader (Bien and Middleton 1996; Galanopoulos 2010). Kazantzakis was a modernist thinker but chose a phenomenological way to narrate his ideas (Bien 2007a, 2007b). He gained international reputation for his capacity to bring epistemological and ontological perspectives into a single grand metanarrative (Bien 2007b, 2007b). Kazantzakis realized modernity's limitations and anticipated postmodern strategies for reading and living (Bien 1998). His selective use of symbols transcend through time and space (Dombrowski 2010). The epitome of Kazantzakis's work was the experience of the human struggle in the context of man's experience of (a) void, (b) creaturely existence, (c) meaning and (d) death (Beaton 1998). His use of imagery sought to challenge already established norms with the intention to generate reflexivity about the meaning of existence itself (Bien 1963; Bien 2007a; Calotychos 2010). His work came under severe criticism because of its alleged transgression against the religious and political establishment of his day (Racheotes 1991; Bien 2007a, 2007b; Arkoudeas 2015). He was perceived as an enemy of the state and accused of threatening the integrity of the Greek government and Eastern Christianity (Bien 1998; Middleton 2000, 2007). The struggle led to political opposition and eventually prevented him from being awarded the Nobel Prize (Bien 2007a, 2007b; Arkoudeas 2015). Despite his own obstacles, Kazantzakis depicted the human struggle within the wider arena of society where organizations are found in tension with the individual's struggle for meaning and selfaffirmation (Kazantzakis 1952, 1960a, 1960b, 1979). Even though his literary works are widely recognized and have gained growing recognition within the academic community, no effort has been made to translate the novelty of his work to the study of organizations.

\section{Phenomenology and the imagery of process and content relationships}

An overarching motif underpinning Kazantzakis's works is the point of the human struggle in which opposing tensions permeate (Racheotes 1991; Middleton 1998). Tensions between content and process, certainty and uncertainty, stability and instability, life and death remain seminal literary motifs of his works (Middleton 2000). Kazantzakis's intention was not only to dominate the plots of his narratives with captivating stories but to generate opportunities for understanding phenomenological transitions of the human experience of being and becoming, but also the absence of being (i.e., non-being) (Middleton 2007, 2010). The attempt to unravel the significance behind his system of thinking remains challenging (Owens 1996). In contrast to the development of a formal academic approach, Kazantzakis decided to communicate his ideas through stories. Following his emphasis on the experience of human existence, Kazantzakis used literary works as platforms for building up a systemic exposition of his thinking (Paschalis 2010). In the course of his works, his attention was placed on the constitution of the different stages of existence that involve a struggle for meaning (Petrakou 2010). Three stages are part of a greater existential development and summarize 
the main premises of his thinking: first, the impulse of existence (i.e., élan vital) as an inherent quality found in all forms of human activity and the desires towards the act of creation (Bien 2007a); second, the position of the individual self in experiencing an existential struggle to come to terms with the fleeting reality of creaturely existence whilst challenging the sense of permanence (Dossor 2002); and, third, the growing realization of one's timely development leading to an evident and yet ill-understood separation from the world (Dombrowski 2010). For Kazantzakis, the human desire to bring forth into existence permeated as a metaphysical need to move above and beyond the necessity to produce in the physical/material world. However, the experience of separation from materiality becomes an adverse reality that challenges one's sense of permanence (Galanopoulos 2010). In translating the above motifs I use a typology based on the development of existence and its transitions between different states of existence. These states are discussed under three headings, namely (a) relatedness, (b) affirmation and (c) temporality. The discussion on each separate state illustrates Kazantzakis's thinking concerning the ongoing struggle between matter and spirit as it is conditioned within the transitions of the individual self. A primary thread of his premise is the presentation of two opposing tensions. First, the human capacity to create in the physical world is underpinned by a strong sense of permanence that corresponds to an existential impulse that ultimately cannot be controlled for what it is (Kazantzakis 1960a, $1960 \mathrm{~b}, 1979)$. Second, the timely development of one's development constantly faces the grim reality of one's own temporality. This tension operates within the individual self and requires the capacity of the individual to transform one's development in the making of her/his life transitions (Maskaleris 2010). This can be done by developing an understanding of life as a rite of passage (Bien and Middleton 1996). An emphasis on transitions is rooted in the belief that the need for organizing but also production is underpinned by an existential impulse, namely the élan vital (Bien and Middleton 1996). The development of a relationship with a creaturely existence indicates an internalization of permanence as an inherent quality found in the human self. However, for Kazantzakis the individuals runs the risk of losing sight of the temporality of existence, thereby undermining the significance of temporality itself. Kazantzakis's emphasis on the making of transitions is designed to illustrate the experience in which a heightening tension between content and process, matter and spirit, and life and death reaches an impasse and demands some form of resolution (Bien 1963; Beaton 1998). For example, an emphasis on affirmation is made to illustrate the development of the human virtue in which the individual is able to commit to a higher purpose without being merely confined by earthly demands (Bien 2012). The development of courage is underpinned by a moral capacity to withstand unknown adversities. For Kazantzakis, the self remains the single entity that needs to face the limitations of creaturely existence and yet must work with them and move beyond them (Kazantzakis 1952, 1960a). Existence cannot become a process fully attached to materiality because it moves into a developmental process where it recognizes that ultimately it remains a timely and temporary activity that can perish (Kazantzakis 1960b, 1979). However, such realization generates new concerns about the value of existence itself and the directionality with which different forms of physical production and consumption occur. Hence, Kazantzakis addresses the content-process dichotomy through the lens of the human experience, where the capacity to create in the physical world needs to be seen in direct and ongoing relation to an inner realm of one's never-lapsing existential concerns (Kazantzakis 1979). Kazantzakis believes that the failure to recognize the transitoriness of a creaturely existence provides an ineffective approach to the management of human progress. Hence, 
his aim is to demonstrate that the power of creaturely existence is situated in the decisionmaking realm of the individual self. It offers the opportunity to deploy alternative metaphors for understanding the relationship between content and process and these are made evident during different states of one's existence. Hence, I argue that a theorization of transitionality through Kazantzakis advances prior considerations of the dichotomy between content and process because the human self exerts a primary role in the development of her/his associations with entities and processes. Such a view carries implications for the study of organizations and the creative deployment of metaphors for understanding their role and function.

\section{Relatedness}

Coming from a process philosophy and deeply influenced by the works of his tutor Henri Bergson (Bien and Middleton 1996), Kazantzakis's attention was constantly situated in the existential implications of the concept of élan vital. An emphasis on the ontology of being is carefully crafted throughout his literary writings. For Kazantzakis, ontology is defined as the study of the human existence, situated within the unexcepted currents of life and emerging from the Bergsonian idea of the élan vital. Relatedness is defined as the experience of the present where the individual is not only developing but also internalizing relationships between objects and subjects that eventually come to define her/his existence. However, for Kazantzakis (1979), to relate within a never-ending process raises new questions about the meaning of existence and the struggle with ambiguity. The creative element of his work is demonstrated in the presentation of relatedness as a process directed by the decision-making power of the individual. In exposing his system of thinking, Kazantzakis (1960a, 1960b) seeks to develop a world view that can accommodate the wide range of human incidents within a homogenous framework of understanding. Through a creative constitution of narratives Kazantzakis deploys a phenomenological approach for capturing the timely development of events and the meanings associated with those events. Kazantzakis paid considerable care to projecting a range of ill-reflected tensions (Middleton 1998) that constantly move his actors and stretch to the boundaries between materiality and existence. Hence, relatedness is developed through an exposition of the human struggle to identify a position within a meaningless world. However, relatedness is also an experience that is directed through one's experience and management of existence heightened during the course of one's aging and self-development. Kazantzakis's goal is to raise knowledge of the human experience within a polemic of different contestations that eventually seek an existential resolution outlet. Narratives do not serve solely as a literary vehicle for communicating information (Middleton 2000). Instead, narratives enabled Kazantzakis to present the constitution of a system of thought in which an exposition of the human experience of relatedness remains a timely activity. Furthermore, relatedness remains an evolving phenomenon that triggers different reactions at different points in one's life development. This element of his work underpins a progressive development of different images situated between one's perceptions of being and becoming (Dombrowski 2010). Here, material entities and processes are found in constant tension. It is as if they are guided by an outer force that almost forces and regulates this development over time. The constitution of a process and structure analogy enabled Kazantzakis to make specific assertions about the personalization of the impulse of existence whilst identifying generic impulses that apply to all humanity. Hence, narratives enabled Kazantzakis to develop a wide spectrum of explanations where the development of an 
awakening experience emerges through one's self-insight (Kazantzakis 1979). This is the outcome of a struggle where different perspectives offer a synthesis of different images that together integrate opposite forces. However, such literary images serve as an arena for presenting a contestation of different perspectives that together challenge prior dichotomies whilst seeking new resolutions. For Kazantzakis, to relate is identified with a strong conviction about the direction that someone needs to take. Kazantzakis identified that a sense of directionality is often forced onto the individual and this creates new constraints for internally seeking a direction in compliance with the eternal struggle of process. In his work Report to Greco, Kazantzakis $(1965,273)$ refers to his own experience from visiting the Eastern Orthodox monks at Mount Athos. In discussing his encounter with the monks, the inner struggle between good and evil shifted from being a subject of contestation with the Devil alone to now also becoming a contestation with God. Kazantzakis recounted a private conversation with a particular monk on the experience of the human struggle. Kazantzakis asked the Orthodox monk:

'Do you still struggle with the devil father Makarios?'...'I now struggle with God ... and do you expect to win? ... I expect to lose'. (Kazantzakis 1965, 273)

This brief conversation demonstrates the individual monk's change of understanding through his own struggles. The Eastern Orthodox monk reaches a very distinct form of a resolution that cannot be understood if it is not experienced for what it is. The contrast between materiality and the existential tension of the self remains a key consideration in Kazantzakis's work. The capacity to create in the material world constitutes only an outer extension of a deeper desire to create permanence against temporality (Kazantzakis 1952, 1960a, 1960b). Bringing something forth into existence is a symbolic act of creating order. Such an endeavour enabled Kazantzakis to deploy a metanarrative that moves from (a) the tangible and limited artefacts towards (b) the intangible and spiritual drives (Petrolle 1993; Galanopoulos 2010; Paschalis 2010). Kazantzakis made the effort to accommodate abstract and specific relationships between all contents and all processes (Bien 2007a, 2007b). Such a literary method remains profound because matter and spirit constitute primitive elements in which both are needed to create something. A struggle with materiality (Hess 2012) is by inference a struggle with the fundamental premise of the experience of how work is understood in organizations. After all, human capital is the primary means by which any form of production is accomplished (Kostera 2012). Bringing forth into existence remains a central topic in the literature and interprets the nuances of work in terms of performance, achievement, growth, resource utilization, branding etc. By engaging with the processual quality of transitoriness (Höpfl 2005; Hugo, Kuiper, and Houweling 2011) Kazantzakis was able to identify the flow and development of existential concerns as these are situated in different symbolic motifs and at different points in one's development (Middleton 1994). Morgan's (1986) metaphor representations advance prior conceptualizations of the constructive usefulness of organizations through the creative scope of the different schemata. However, the human existence of those schemata seems to be tightly confined by the entitative constitution to which they are subscribed in the first place (Schoeneborn, Vásquez, and Cornerlissen 2016). Hence, an organization is believed to represent a psychic prison because of its ongoing power to control resources but also how its intentions need to be fulfilled by its organizational members (Morgan 1986). Aspirations of success and growth are consciously or 
unconsciously internalized within organizations' members (Hochschild 2012). The success of organizations through the deployment of organizations' members is closely related to the human capacity to maintain power structures that sustain successful outputs (Baritz 2005). This paradigm contrasts with Kazantzakis's view of relatedness, where the individual self exerts a new level of impact through the making of her/his inner associations. These associations cannot be fully controlled by the organization as they are emergent from within the individual self. Kazantzakis identifies the experience of organizations as a rite of passage where the struggle with materiality comprises an event that constantly moves under its own development (Bien 2012). The organization can be perceived as the entity that provides stability for the individual but at the same time can become the entity that threatens her/him (Schatzki 2005; Brook 2013). Kazantzakis (1960b) underlined the fragility of the interpretation of any form of schemata and, in particular, the sensitivity with which the schemata's internalization takes place in the individual's experience. This view carries implications for understanding the power of organizations as entitative structures that can regulate meaning but also become void of meanings.

\section{Affirmation}

In Kazantzakis's thinking, the development of a heightening tension between individuals and organizations reaches a new state of development (Kazantzakis 1960b). Overwhelmed by the impulse of existence itself and driven by his desire to explain how existence is connected to a cosmic and evolutionary development, Kazantzakis (1979) designed his literary works around the individual's struggle to transcend norms. His method in presenting the development of inner tensions is in light of an alternative set of tensions found in the individual self. Affirmation is defined as the development of the human capacity to sustain one's self despite the forces that negate it (Kazantzakis 1960a, 1960b, 1965). Kazantzakis's exposition on affirmation becomes a new conceptual territory through which he is seeking to identify with those inner forces responsible for organizing how contestations are situated in individuals' thoughts and actions. The development of affirmation is not an individual choice that is made at a single point in time. Instead, it is a process that undergoes time and development before it comes to fruition. Kazantzakis's (1965) development of affirmation is situated within prior historic, mythical and religious literary expositions of earlier writings. His argument is that the human self reaches a new point of development when it realizes that the self is only able to transcend circumstances by identifying with a specific value of the self as a property not found in other entities. Through his own study with Bergson, Kazantzakis (1965) identifies that a person undergoes a creative and transformative process when she/he is at tension with organizations. The act of self-affirmation is defined as a moral act where the individual is seeking to affirm existence against those forces that negate and challenge it. A state of affirmation indicates a point of development because the individual is working through a set of oppositions and is encouraged to associate with self-qualities that remain hidden. For example, the human capacity to exert a sense of affirmation against opposition requires a sense of directionality, which is challenged by the composition of the tensions themselves. This can be viewed in the relationship between employees and management and in employees' decisions to go against policies and procedures. The capacity to exert resistance is situated within a wider sent of judgements where benefits and losses are carefully considered. Kazantzakis does not present affirmation as merely the exercise of opposition in the context of one's disagreement. Instead, he identifies that affirmation regulates the 
development of direction in the making of one's current and future identity. This development is not an ad hoc event but a long-term process that has decisive importance for the life and fate of the individual, but also has special importance for humanity (Maskaleris 2010). Kazantzakis's presentation of affirmation is illustrated in the deployment of religious figures where the exercise of resistance, and even sacrifice of one's self, is willingly made for achieving a higher end. The pains of this decision and associated consequences are contrasted with the immediate benefits that could be gained had this decision not been made. For example, in his book The Last Temptation of Christ (Kazantzakis 1960b) a young carpenter is portrayed as a skilful individual who manufactures crosses for the enemy (i.e., the Romans). He is suddenly confronted by his friend Judas, who senses that the carpenter's aspirations are greater than his provocative role in manufacturing crosses for the enemy. At some point, Judas senses that the carpenter starts to consider himself a potential saviour and yet the carpenter remains highly secretive about it. In an angry mood, Judas unexpectedly confronts him, demanding to know his true intensions. His direct questioning is perceived as threatening and patronizing: 'Are you the one? You!?' Through this incident Kazantzakis captures the perception of one's identity as being conditioned by the immediate social environment but also conditioned by one's aspirations to become someone who is not for the well-being of others. Judas's strong tone almost forces the unidentified young man to give a range of excuses for not being the Messiah. However, the young man is going through a struggle of identity reconciliation. Even though he seems to conform to the expectations of his local community, over time the carpenter comes to reject them. He accepts his role as being the Christ. This is an experience created by him rather than a property given to him. In this way the Christ is appropriating his own struggle, which gradually enables him to go to the cross and offer himself as the ultimate sacrifice for others. Following Bergson's (1911) process philosophy, Kazantzakis elevates the role of affirmation as the most important organizing pathway that enables man to tackle existential concerns in transition (Calotychos 2010; Galanopoulos 2010). As Bien and Middleton (1996, 11) note, such conviction started when 'Bergson taught Kazantzakis that the élan vital first clothes itself in flesh and then divests itself'. The power of affirmation within a phenomenological approach is found in its capacity to reconcile being and non-being (i.e., the absence of being). The study of affirmation is a theme already situated within a Bergsonian process philosophy and is connected with a greater cosmic evolutionary development. However, Kazantzakis builds on this motif. He sees man represented as a 'little worm' who is thrown onto the ground and 'eats mud', constantly limited by time and space (Jacobs 2005). Yet, the paradox of her/his condition is that this same individual is capable of reaching the highest level of existence, namely God. The contrast between the 'liminality' of human existence within the confinements of society and the moral 'capacity' to overcome the boundaries created by the constitution of society suggests a new level of moral responsibility. For Kazantzakis, affirmation begins at the point of realizing that the individual is a symbolic arena of opposing forces. Against ongoing contestations the individual has the responsibility to transform them into a higher state of existence through struggle. Thus, Kazantzakis's conceptual contribution to affirmation advances Morgan's $(1980,1983,1986)$ metatheoretical deployment of metaphors in alleviating the power of the individual self to challenge power ties that seem to be impossible to challenge. Kazantzakis's works suggest how the disruptive forces found in affirmation suggest a greater impact that is not rooted in the formal position of the individuals who performed them. Instead, it is situated in the inherent power of the act itself, which has the 
capacity to generate disruption and even challenge the well-being of a social system. Existential considerations in the development of one's identity are often subdued through an emphasis on the organizational requirements that determine the development of the specific identity accounts (Willmott 1997; Searle 2009). Hence, an affirmation of the 'self' offers a power-comparative contrast with the organization as an entity that operates through its concentrated resources and power structures. This view extends to supporting the unprecedented impact of work by individuals like Edward Snowden and Aaron Swartz.

\section{Temporality}

For Kazantzakis there is an ongoing struggle between existence and materiality. Both elements exist in an interdependent relationship. They enable processes to occur as changes over time. Yet, the tension between the two entities is made evident when acknowledging the temporality of human existence as a liminal process that carries an ontological end (Kazantzaki 1968). Since the study of process represents the core element of a new synthesis generated through an ongoing collision between processes (Hernes and Maitlis 2010), change remains an inevitable reality that cannot be escaped from in one's creaturely existence (Heidegger 1927; Giddens 1984). The struggle between life and death is manifested in the development of a wider tension between (a) the need to create in the material world, and at the same time (b) to operate within the temporal span of existence. In advancing the Bergsonian process philosophy, Kazantzakis is faced with the person's management of existence as a response to acknowledging the temporality of existence itself. In stretching the philosophical paradigm that supported the development of his earlier roots, Kazantzakis identifies that the liminality of existence actually presents a new opportunity to reconsider the meaning of human development, not only as a system but also as a human experience in transition. This phenomenological endeavour can be materialized through one's long-term engagement with the underpinnings of one's experience of separation from materiality (Galanopoulos 2010). For Kazantzakis (1965), the possibility of non-existence is not considered a finite event that will take place in the future. Instead, it is a process that needs to challenge the engagement of one's existence within the timely space of temporality (Jacobs 2005). The management of one's experience in the present gains new significance for the future and when it is seen in light of the upcoming absence of one's existence. In an effort to capture the friction created between opposites (e.g., life and death, or being and nonbeing), Kazantzakis constructs his plots so that the management of temporality becomes an event of the present (Middleton 2005). This act is illustrated through a creative range of literary means, including the Abyss and the Cretan Glance (Kazantzakis 1965). For example, the imagery of the Abyss is rooted in earlier biblical and mythological contexts where man is confronted by an unavoidable void that cannot be escaped for what it is. The Abyss is complemented by a different imagery schema, the Cretan Glance. Its purpose is to alleviate the position of one's outlook and to come to terms with the Abyss. By deploying these literary metaphors, Kazantzakis dwells on the development of an attitude that concerns not only the individual as a unit but also the development of humanity (Bien 2007b). The Cretan Glance represents the development of a new state of being that can account for the absurdities of life but yet work through them (Bien and Middleton 1996). The desire to account for temporality is driven by his earlier engagement with a Bergsonian understanding of process where life and death remain interchangeable entities and the individual has the responsibility of diffusing their force within the territory of creaturely existence (Galanopoulos 2010). In expositing a 
phenomenological position of separation from attachment, Kazantzakis examines the process of internalizing images of permanence through the experience of self-creation and selfdevelopment. However, in doing so, Kazantzakis understands that the desire to achieve permanence, especially within a society dominated by a steep growth of production, innovation and technology, does not only culminate in the production of the material world per se (Bien 2007a, 2007b). Instead, it carries a deeper connotation: transcending the anguish of temporality into materiality. Despite this experience not being fully realized at the time the individual is bringing forth into existence, it nevertheless becomes apparent in the fleeting course of time. The fear of temporality is made evident as a process of retrospection, where the possibility of the absence of one's being becomes the ultimate threat to the representation of existence itself. Hence, accounting for a final and permanent separation of materiality raises new existential concerns about the social, economic and political structures on which society is creating order (Middleton 1994, 1998, 2000, 2007). For Kazantzakis, the rigid failure of society to account for the weight of its own temporality undermines the painful realities of human existence (Bien 2007b). The implications of such a development undermine the responsibility of the individual for grabbling with life and death through the realities of existence (Bien 2007a).

\section{Theoretical implications}

Following recent attention on Morgan's $(1980,1986,1996)$ work on organizations as images, there is growing interest on the relationship between content and process relationships situated in these images (Schoeneborn, Vásquez, and Cornerlissen 2016). Despite Morgan's conceptual advancements, still little is known about the entitative constitution of organizations (Knights 2005) in regulating human experiences and in light of their organizational structure and expectations (Kostera 2012). Studies on the human receptivity to organizations triggered new research interest in the embodiment of organizations (Weick 1979, 1995; Oswick, Keenoy, and Grant 2002; Gergen 2009). In particular, earlier attempts that sought to theorize the relationship between meaning and existence focused on the development of the different stages of self-development (Kudesia forthcoming). For example, Berger and Luckmann (1966) suggest the role of (a) internalization, (b) externalization and (c) objectification as different states that explain the inner and outer representation of images. This conceptualization explains the presence of an ongoing and transient development responsible for regulating the flow between entities and processes. For example, the experience of objectification suggests that the experience of an event is transformed from an inner property into outer symbols. Ambiguous properties are codified through the making of tangible representations. However, ambiguous properties are also internalized, shifting away before they can be accepted and supported by other members. This view was further developed through Weick's (1995) concept of reification, in which the individual is assuming an active role by self-enacting the ambiguous organizational processes through the performative space of her/his own existence. The individual is responsible for a process of transformation where the intangible and ambiguous are converted into tangible and 'real' entities. Despite the conceptual advancements made in the prior literature, still little is known about the constitution of a conceptual paradigm that can account for how individual nuances can be connected to a wider spectrum of content-process tensions situated in organizations and their members. In developing Kazantzakis's philosophy, I argue that a conceptualization of transitionality advances organization theory in three ways. First, it identifies that the 
structural relationships between a content and process tension is situated within the human experience but also triggered through the human interactions with organizations. In contrast to Morgan's (1986) entitative interpretation of organizations, a conceptualization of process via Kazantzakis is rooted in a wider existential repertoire where permanence and temporality remain in tension and constitute greater forces that operate and transcend the nuances behind the human experience. This argument suggests that organizations represent social entities that remain emblems of permanence, yet their entitative qualities trigger new reactions that are connected to an inherent existential struggle. This struggle is an impulse that forces man to struggle not only for existence but also for assurance about the creation of permanence itself. Thus, a conceptualization of transitionality, viewed through the lens of a typology that identifies different states of existence, suggests that individuals play a primary role in customizing content and process tensions within their own experience. Such tensions are intensified during the different states of development but are also embedded in the manner in which methods of production are organized within organizations. For example, the design and championing of process entities like achievement and success are situated within a specific context of interaction that is organization-centred (Czarniawska and Joerges 1995; Kostera 2012). To an organization, success means advancing the organization's goals. An exploration of Kazantzakis's thought demonstrates that the act of production remains a metaphysical need triggered by two elements. First, it is triggered by an inherent impulse for creation that challenges the individual's confrontation with materiality. Second, it is triggered by the impulse of self-aspiration, where an effort towards permanence complements the temporal span of existence. An experience of organizations as metaphors situated within Morgan's (1986) typology suggests that the human experience is confined to content-process associations regulated by intentions emerging from the metaphor itself. For Kazantzakis, a content-process tension is intertwined within a permanence-temporality tension. This process remains integral throughout all forms of human existence and cannot be contained in organizations or by organizations as the entities that regulate this relationship. Hence, a theorization of transitionality is conceptualized as the process that is seeking to engage the individual self as the primary entity responsible for customizing nuanced interactions and in the course of the development of one's life. Kazantzakis's process philosophy advances theoretical conceptualizations that further phenomenological thinking as previously found in Bergson and Heidegger. However, this is done by furthering the power of the experience of one's existential struggles and these are reflected through the creative power of literary narratives. Kazantzakis shows that, apart from a systematic analysis of phenomenology, an engagement with literary narratives demonstrates that these can used as instruments for advancing insights into the transitions in the struggle between content and process. A theorization on relatedness explains that there are different positions in one's process of selfdevelopment that cannot be accounted for at a particular point in one's existence. Time exerts considerable force on the constitution of the self, also causing the position and perception of the world to change. This view suggests that a consideration of reification, as developed by Weick $(1995,2001)$, is not exerted as an individual choice. Instead, it is conditioned by the forces of permanence and temporality within the parameters of the individual self. This Kazantzakian insight advances an alternative conceptualization of the order and sequence of human transitions that challenges the fashion in which an organization's structures and operations are extended to its members and how they are experienced within the organization. In particular, the human experience of organizations cannot be interpreted as 
an entity that remains receptive and accommodating to the direction and control exerted by the organization. Instead, it is an experience that grows through selfcentred struggles. The regulation of the organization becomes contingent only on the realization of the permanencetemporality tension as it emerges through one's own life transitions. Following current emphasis on the study of integration between organizations and their members, it is also suggested that a state of perceived alignment remains necessary for the success of an organization (Hernes and Maitlis 2010). This view advances the development of a new state of strategic alignment, where an organization's members are invited to be supportive of the organization's actions (Hochschild 1997, 2003, 2012). Furthermore, it is suggested that the state of integration between the organizational self (Pratt and Kraatz 2009) and the members' individual selves (Hochschild 2012) remains detrimental for the overall performance of the organization as a coherent unit in action (Pratt and Kraatz 2009; Brook 2013). In light of Kazantzakis's conceptual expositions, it can be argued that a need for integration is fostered by a greater existential need to secure a predictable and stable working environment. However, such a view undermines the human reactions that emerge from this very interaction. Thus, a conceptualization of transitionality shows that the weight of those deeper human considerations can be understood as responsible for the creation of permanence, which itself is to be understood as the desire for continuity through extrapolating the humancreated entities that can withstand the passing of time. In this sense, permanence is associated with the human desire to establish actions that carry a predictable orientation in the production and distribution of outcomes. Kazantzakis demonstrated that the human reaction for permanence is triggered and reinforced by a realization of temporality and the need to separate from it. Hence, the possibility of an individual exerting rejection of permanence might be triggered not by the individual actions situated in the organization and in seeking to meet its goals but, rather, by the individual's self growing an awareness of the limitations of a content-oriented development that gradually comes to ignore life as a temporal activity. Hence, a consideration of transitionality identifies that the development of an amounting confidence in organizations becomes heightened through the creation of permanence. However, this seeming permanence acts as prime cause to generate new and different accounts of deeper tensions between and within organizations' members.

A second contribution made through Kazantzakis's work is found in the conceptualization of the self as the entity that unites but also needs to regulate transitions between permanence and temporality. An emphasis on the self should not be understood as merely an attempt to satisfy one's needs or satisfy one's needs at the expense of others. Instead, a conceptualization of affirmation suggests a self-creative process in which the individual seeks to organize reactions that challenge the sense of stability and continuation. The self is the entity that acts as the nucleus of decision-making considerations. It is predominately concerned with the possibility of being and non-being (Tillich 1956). Moreover, it exerts directionality in the appropriation of tensions and in an effort to affirm existence despite those forces that negate the self. As with Bergson (1911), Heidegger (1927) and more recently Tillich (1956), the affirmation of one's self is considered a moral act where the internalization of outer forces are creatively transformed through the makings of the individual's judgement. In organization theory, a conceptualization of affirmation/courage (Koerner 2014) is further heightened through a contestation of different images where the organization can act as a powerful social and political entity (e.g., a psychic prison) that can regulate the conscious and 
unconscious traits. Kazantzakis's personal experience of this tension was heightened through his long-term decision to adopt literary and religious images that could foster a clearer understanding of the person's existential struggle. The literary schema did not conform to the religious establishment of his day and faced rejection. Through his own struggles Kazantzakis identified that the human self constitutes the most valuable entity, whose capacity to reach a higher set of ideals can only become possible through an experience of appropriating the inner struggle and in light of the capacity to transform it. It is for this reason that a constitution of affirmation through an understanding of courage is viewed as a moral act. It carries the power to transcend the self beyond the organized entities of her/his time. Studies about employees as social capital that carries potential for innovation, creativity, imagination, leadership etc. are attracting increasing attention in the literature (Michel 2014). Researchers have identified that the development of an awareness about a desired course of action requires the prior act of selfcommitment (Schatzki 2005; Koerner 2014). Self-determination in leadership remains an eclectic process where mindfulness is situated against interpersonal sociopolitical forces that challenge its development (Weick 1995; Brook 2013). The decision of the individual to affirm or reject a course of action is contrasted with the organization's interests, either supporting or disregarding the creative capacity of the individual to bring change (Miceli, Near, and Dworkin 2008). For Kazantzakis, the development of a capacity towards the making of self-affirmation is predominately rooted within an internalization of a deeper permanence-temporality tension that ultimately seeks an existential resolution outlet. In this way, the individual's act of affirmation is found in the capacity to streamline but also transform that which remains highly individualistic yet capable of having transcending power on entities outside the individual. Furthermore, a tension between the individual and the organized system of society is demonstrated in the capacity to undertake risky decisions (Smith 2001; Palmer 2012). For example, some organizations' members (e.g., whistleblowers) exert resistance against a coordinated power structure that ultimately remains more capable than the individual (Miceli, Near, and Dworkin 2008). A range of individuals that resisted organizations (e.g., Sherron Watkins, Edward Snowden) were perceived as threatening to the greater establishment and were even treated as traitors. Despite the wide proliferation of the political motives that might influence an organization's member to exert resistance, it is also evident that a similar development happens in individuals who support the interests of the organization even where the firm commits some misconduct (McDonald and Robinson 2009). However, the powerless individual is contrasted with the powerful organization. An act of self-affirmation can be perceived as threatening to the integrity of an organization, despite the direct contrast of the different power structures. Such a threat is situated within a polemic of different interpretations of what is 'right' or 'wrong' (Palmer 2012). For Kazantzakis, the advance towards one's state of affirmation remains the aftermath of the development of a primordial inner tension (Bien and Middleton 1996). It offers a unique opportunity for the individual to express that which remain integral part of a cosmic struggle (Bien 2007a). Furthermore, it contributes to the authenticity of the human experience, which itself alleviates the significance of one's sense of being. A third theoretical contribution to the literature is made in the conceptualization of temporality as a state in which the absence of one's being acts with force to challenge prior considerations about the value of permanence. Kazantzakis's emphasis on temporality is not intended to generate a nihilistic representation of the human existence (Dossor 2002). Instead, he uses it as a tool to trigger considerations about the boundaries of being with the intention of generating a creative set of reactions that 
can reaffirm the importance of existence for what it is, namely a temporal activity. Thus, a conceptualization of temporality challenges the boundaries of existence because it is an element barely integrated into conceptualizations about human development and progress (Dombrowski 2010). However, the development of a phenomenological exposition that can accommodate the weight of the temporality of existence suggests a new level of consideration about the meaning of permanence and its translation within the different forms of organizing and production. A creative retrospection of temporality, found in the internalization of the experience of permanence, is a property that can withstand the flow of time itself. Hence, Kazantzakis did not seek to refute the decision to produce and develop through the deployment of resources and through organizations. However, he did seek to challenge the extent to which a consideration of temporality can act as a catalyst to enable the individual to reconsider one's ultimate approximation to permanence. Despite the Bergsonian development in Kazantzakis's thinking, where the ongoing flow of change remains the overarching process that overpowers all content and process interactions, a conceptualization of transitionality shifts the focus to the social structures by which aspirations of permanence are established in organizations. Considerations of temporality are often associated as negative. They demonstrate pessimistic reactions to the possibility of human progress (Höpfl 2005; Putnam and Boys 2006). However, Kazantzakis challenged this position through his works. He demonstrated that a consideration of existence, when performed through an awareness of temporality, acts as an organizing force that constitutes a seminal platform for the evaluation of human development and progress. This view challenges current assumptions about the development of human progress situated within a theorization of organization as systems of production and where the mobilization of human capital advances and extends organizational success (Boje 2001, 2014).

\section{Conclusion}

Following prior calls for further research on the relationship between content and process and in light of Morgan's (1980) metaphors of organizations (Schoeneborn, Vásquez, and Cornerlissen 2016), this paper advances conceptualizations through the phenomenology of Nikos Kazantzakis. In interpreting the relevance of his work I concentrate on the case of the transitionality between different progressive states of existence. A theorization of transitionality suggests that content and process transitions follow differ ent states of existence. This development challenges the dominance by which the images' entitative attributes are associated in organizations and conditioned within the course of one's existence. Kazantzakis's work demonstrates that a struggle between content and process remains part of a wider tension that remains highly personal and existential. A state of relatedness identifies a position of existence where associations with physical and nonphysical phenomena go through different transitions and these are regulated by the life-path of existence itself. Kazantzakis identified that the struggle for achieving permanence against life's time span is a metaphysical need that often undermines the constraints of creaturely existence (Bien and Middleton 1996). Kazantzakis noted that the capacity of the individual self to accommodate and transform this struggle enables her/him to identify with the liminalities of existence and to work through them. By dedicating large parts of his work to reenacting the experience of affirmation and separation from materiality, Kazantzakis was interested in exposing transitions that offer people alternative perspectives for understanding their struggle towards existence (Middleton 2005, 2007, 2010). The conceptual implications 
of his work could be viewed in light of a theory of transitionality where the development of an awareness of the different states of existence offers new outlets for understanding the confinement of organizations as systems that can exert influence on human behaviour. Kazantzakis's work demonstrates that the struggle between content and process advances understanding of the process by which the individual develops different representations of organizations. This understanding carries implications for understanding the use of Morgan's (1986) metaphors. In particular, Kazantzakis demonstrates that people exert considerable force in the management of their existence through a realization of the different progressive states of their lives but also in realizing death. This view carries theoretical and practical implications for understanding the management of tensions through which organizations support the continuity of their members but also threaten their existence. Such threat does not necessarily come from the organization itself but from the associations that the individual creates with the entitative and process aspects of her/his interaction with the organization as an entity in transition (Weick 2011). A struggle with organizations is a metaphor for an existential struggle with materiality but also with the attachment to the symbolic permanence with which materiality is envisaged at the time of production (Bien 2007a). Such a conceptualization positions the work of the individual self above the constitution of organizations as metaphors. The individual's regulative capacity to identify with an existential repertoire of motifs moves beyond existence represented as a temporal activity that has a beginning and an end. A final contribution made by Kazantzakis is made by eliciting the creative but also destructive power of the human will to bring into existence something which carries greater permanence and stability than the immaterial consideration of existence. In a similar way to Bergson, Kazantzakis identified with the human frustration and the possibility of meaninglessness deriving from the human incapacity to accommodate the absurdity of life within the different domains of existence. A phenomenological interpretation of human progress, in light of relatedness, affirmation and temporality, suggests that an appropriation of existence requires different qualities, which are not made evident in the current metaphoric articulation of organizations, that is, as entities that contribute to the creation and development of fundamental meaning-making associations.

\section{Acknowledgement}

The author remains sincerely grateful to Professor Darren J. N. Middleton for his support, insights and constructive comments on the paper. I would like to also thank Dr Max Tookey for his constructive comments and suggested edits.

\section{Disclosure statement}

No potential conflict of interest was reported by the author.

\section{References}

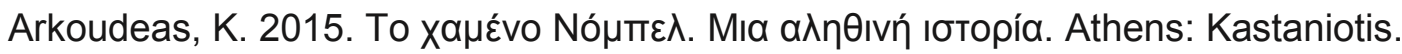

Baritz, L. 2005. "The Servants of Power." In Critical Management Studies. A Reader, edited by C. Gray, and H. Willmott, 29-45. Oxford: Oxford University Press.

Beaton, R. 1998. "Of Crete and Other Demons: A Reading of Kazantzakis's Freedom and Death." Journal of Modern Greek Studies 16 (2): 195-220.

Berger, P. L., and T. Luckmann. 1966. The Social Construction of Reality: A Treatise in the Sociology of Knowledge. Garden City, NY: Doubleday. 
Bergson, H. 1911. Creative Evolution. (A. Mitchell, Trans.). New York: Dover.

Bien, P. 1963. "Zorba the Greek, Nietzsche, and the Perennial Greek Predicament." Antioch Review 25: 147-163.

Bien, P. 1998. The Last Temptation of Christ. Nikos Kazantzakis. New York: Simon and Schuster.

Bien, P. 2007a. Kazantzakis: Politics of the Spirit. Vol. 1. Princeton, NJ: Princeton University Press.

Bien, P. 2007b. Kazantzakis: Politics of the Spirit. Vol. 2. Princeton, NJ: Princeton University Press.

Bien, P., ed. 2012. The Selected Letters of Nikos Kazantzakis. Princeton, NJ: Princeton University Press.

Bien, P., and D. J. N. Middleton. 1996. God's Struggler: Religion in the Writings of Nikos Kazantzakis. Macon, GA: Mercer University Press.

Boje, D. M. 1991. "The Storytelling Organization: A Study of Story Performance in an OfficeSupply Firm.” Administrative Science Quarterly 36: 106-126.

Boje, D. M. 2001. Narrative Methods for Organizational and Communication Research. London: Sage.

Boje, D. M. 2014. Storytelling Organizational Practices: Managing in the Quantum Age. London: Routledge.

Brook, P. 2013. "Emotional Labour and the Living Personality at Work: Labour Power, Materialist Subjectivity and the Dialogical Self." Culture and Organization 19 (4): 332-352.

Calotychos, V. 2010. "Kazantzakis the Greek?: Travel and Leisure, Hunger and Pathos, Localism and Cosmopolitanism Journeying." Journal of Modern Greek Studies 28 (1): 189217.

Czarniawska, B. 1998. A Narrative Approach in Organizational Studies. London: Sage.

Czarniawska, B., and B. Joerges. 1995. "Narration or Science? Collapsing the Division in Organization Studies." Organization 2 (1): 11-33.

Demir, R., and L. O. Lychnell. 2015. "Mangling the Process: A Meta-Theoretical Account of Process Theorizing." Qualitative Research 15 (1): 85-104.

Dombrowski, D. A. 2010. "Why Should we Read Kazantzakis in the Twenty-First Century?: A Constructive (Rather Than Deconstructive) Postmodern Response." Journal of Modern Greek Studies 28 (1): 39-50.

Dossor, H. F. 2002. The Existential Theology of Nikos Kazantzakis. Wallingford, PA: Pendle Hills Publications.

Galanopoulos, C. 2010. "Anti-nihilism in the Thought of Nikos Kazantzakis." Journal of Modern Greek Studies 28 (1): 7-37.

Gergen, K. J. 2009. Relational Being: Beyond Self and Community. Oxford: Oxford University Press.

Giddens, A. 1984. The Constitution of Society. Berkeley: University of California Press.

Heidegger, M. 1927. The Basic Problems of Phenomenology. (A. Hofstadter, Trans.). Indianapolis: Indiana University Press.

Hernes, T., and S. Maitlis. 2010. Process, Sensemaking and Organizing: An Introduction. Oxford: Oxford University Press.

Hess, F. 2012. "The Case for a Contemporary Kazantzakis." Journal of Modern Greek Studies 30 (2): 339-343. 
Hochschild, A. R. 1983. The Managed Heart: Commercialization of Human Feeling. London: University of California Press.

Hochschild, A. R. 1997. The Time Bind: When Work Becomes Home and Home Becomes Work. New York: Metropolitan Books.

Hochschild, A. R. 2003. The Commercialization of Intimate Life: Notes From Home and Work. London: University of California Press.

Hochschild, A. R. 2012. The Outsourced Self: Intimate Life in Market Times. New York: Metropolitan Books.

Holt, R., and J. Sandberg. 2011. "Phenomenology and Organization Theory." In Research in the Sociology of Organizations, Vol 32, edited by H. Tsoukas and R. Chia, 215-250. Bingley, UK: Emerald.

Höpfl, H. 2005. "The Organisation and the Mouth of Hell." Culture and Organization 11 (3): 167-179.

Hugo, L., C. Kuiper, and L. Houweling. 2011. "Live Metaphor: Hardiness and Postcards." Culture and Organization 17 (5): 389-401.

Jacobs, K. A. 2005. "We're all Brothers! All Worm Meat!' A Consideration of Kazantzakis's Zorba the Greek in the Quest for the Just Society." Contemporary Justice Review 8 (2): 229 237.

Kazantzaki, E. N. 1968. Nikos Kazantzakis: A Biography Based on his Letters. (A. Mims, Trans.). New York: Simon and Schuster.

Kazantzakis, N. 1952. Zorba the Greek. Trans. Carl Wildman. New York: Simon and Schuster. Kazantzakis, N. 1960a. The Saviors of God: Spiritual Exercises. (K. Friar, Trans.). New York: Simon and Schuster.

Kazantzakis, N. 1960b. The Last Temptation of Christ. (P. Bien, Trans.). New York: Simon and Schuster.

Kazantzakis, N. 1965. Report to Greco. (P. Bien, Trans.). Oxford: Brunnon Cassiser.

Kazantzakis, N. 1979. The Suffering God: Selected Letters to Galatea and to Papastephanou. (P. Ramp and K. AnghelakiRooke, Trans.). New York, NY: Caratzas.

Knights, D. 2005. "The Disruptive Impact of new Epistemological Location for the Study of Management." In Critical Management Studies: A Reader, edited by C. Gray, and H. Willmott, 60-106. Oxford: Oxford University Press.

Koerner, M. M. 2014. "Courage as Identity Work: Accounts of Workplace Courage." Academy of Management Journal 57 (1): 63-93.

Kostera, M. 2012. Organizations and Archetypes. Cheltenham: Edward Elgar.

Kudesia, Ravi. Forthcoming. "Mindfulness as Metacognitive Practice." Academy of Management Review. doi:10.5465/amr.2015.0333.

Langley, A., C. Smallman, H. Tsoukas, and H. A. Van de Ven. 2013. "Process Studies of Change in Organization Management: Unveiling Temporality, Activity, and Flow." Academy of Management Journal 56 (1): 1-13.

Maskaleris, T. 2010. "The Terrestrial Gospel of Kazantzakis: Inspiration for Saving the Earth." Journal of Modern Greek Studies 28 (1): 263-270.

McDonald, G. L., and P. Robinson. 2009. A Colossal Failure of Common Sense. New York: Crown.

Miceli, P. M., P. Near, and M. T. Dworkin. 2008. Whistle-blowing in Organizations. London: Routledge. 
Michel, A. 2014. "The Mutual Constitution of Persons and Organizations: An Ontological Perspective on Organizational Change." Organization Science 25 (4): 1082-1110.

Middleton, D. J. N. 1994. "Nikos Kazantzakis and Process Theology: Thinking Theologically in a Relational World." Journal of Modern Greek Studies 12 (1): 57-74.

Middleton, D. J. N. 1998. "Apophatic Boldness: Kazantzakis's use of Negation and Silence to Emphasize Theological Mystery." Midwest Quarterly 39 (4): 453-467.

Middleton, D. J. N. 2000. Novel Theology: Nikos Kazantzakis's Encounter with Whiteheadian Process Theism. Macon, Georgia: Mercer University Press.

Middleton, D. J. N., ed. 2005. Scandalizing Jesus. Kazantzakis's The Last Temptation of Christ Fifty Years on. New York and London: Continuum.

Middleton, D. J. N. 2007. Broken Hallelujah: Nikos Kazantzakis and Christian Theology. Plymouth, UK: Lexington Books.

Middleton, D. J. N. 2010. "Reading Kazantzakis in the United States: A Christian Theological Perspective." Journal of Modern Greek Studies 28 (1): 51-67.

Morgan, G. 1980. "Paradigms, Metaphors and Puzzle Solving in Organizational Theory." Administrative Science Quarterly 25 (4): 605-622.

Morgan, G. 1983. "More on Metaphor: Why We Cannot Control Tropes in Administrative Science." Administrative Science Quarterly 28 (4): 601-607.

Morgan, G. 1986. Images of Organization. Beverly Hills, CA: Sage.

Morgan, G. 1989. Creative Organization Theory: A Resourcebook. London: Sage.

Morgan, G. 1993. Imaginization: New Mindsets for Seeing, Organizing and Managing. Newbury Park and San Francisco, CA: Sage Publications.

Morgan, G. 1996. "Is There Anything More to be Said About Metaphor?" In Metaphor and Organizations, edited by D.

Grant, and C. Oswick, 227-240. London: Sage.

Morris, A. J., and C. D. Feldman. 1996. "The Dimensions, Antecedents, and Consequences of Emotional Labour." Academy of Management Review 21 (4): 986-1010.

Nicotera, A. M. 2013. "Organizations as Entitative Beings: Some Ontological Implications of Communicative Constitution." In Organization and Organizing: Materiality, Agency, and Discourse, edited by D. Robichaud, and F. Cooren, 66-89.

New York: Routledge.

Orlikowski, W. J. 2007. "Sociomaterial Practices: Exploring Technology at Work." Organization Studies 28 (9): 1435-1448.

Oswick, C., T. Keenoy, and D. Grant. 2002. "Metaphor and Analogical Reasoning in Organization Theory: Beyond Orthodoxy." Academy of Management Review 27 (2): 294-303. Owens, L. 1996. "Pontius Pilate. Modern man in Search of a Soul." In God's Struggler: Religion in the Writings of Nikos Kazantzakis, edited by P. Bien, and D. J. N. Middleton, 3546. Macon, GA: Mercer University Press.

Palmer, D. 2012. Normal Organizational Wrongdoing: A Critical Analysis of Theories of Misconduct in and by Organizations. New York: Oxford University Press.

Paschalis, M. 2010. "The Relations of Kazantzakis's Kapetan Michalis to Homer's Iliad and Shakespeare's Othello.” Journal of Modern Greek Studies 28 (1): 143-172.

Petrakou, K. 2010. "The Ideological and Aesthetic Perspective in Kazantzakis's Dramas: Is It Still Valid?" Journal of Modern

Greek Studies 28 (1): 105-114. 
Petrolle, E. J. 1993. "Nikos Kazantzakis and the Last Temptation: Irony and Dialectic in a Spiritual Ontology of Body."

Journal of Modern Greek Studies 11 (2): 271-291.

Pratt, G. M., and S. M. Kraatz. 2009. "E Pluribus Unum: Multiple Identities and the 'Organizational Self'." In Exploring Positive

Identities and Organizations: Building a Theoretical and Research Foundation, edited by M.

L. Roberts, and E. J. Dutton, 385-410. New York: Routledge.

Putnam, L. L., and S. Boys. 2006. "Revisiting Metaphors of Organizational Communication." In SAGE Handbook of Organization Studies, edited by S. R. Clegg, C. Hardy, T. B. Lawrence, and W. R. Nord, 541-576. London: Sage.

Racheotes, S. N. 1991. "Theogony and Theodicy: Nikos Kazantzakis and the Mortal Struggle for Salvation." East European Quarterly XVII (3): 363-398.

Reissner, S. C., V. Pagan, and C. Smith. 2011. "'Our Iceberg is Melting': Story, Metaphor and the Management of Organisational Change." Culture and Organization 17 (5): 417-433.

Schatzki, R. T. 2005. "The Sites of Organizations." Organization Studies 26 (3): 465-484.

Schoeneborn, D., C. Vásquez, and J. Cornerlissen. 2016. "Imagining Organization Through Metaphor and Metonymy:

Unpacking the Process-Entity Paradox." Human Relations 69 (4): 915-944.

Searle, J. R. 1979. "Metaphor." In Metaphor and Thought, edited by A. Ortony, 92-123. Cambridge: Cambridge University Press.

Searle, J. R. 2008. "Language and Social Ontology." Theory and Society 37 (5): 443-459.

Shepherd, D. A., and K. M. Sutcliffe. 2015. "The Use of Anthropomorphizing as a Tool for Generating Organizational Theories." Academy of Management Annals 9 (1): 97-142.

Sid, L. 2002. "The Cultural Shadows of Cross Cultural Research: Images of Culture." Culture and Organization 8 (1): 21-34.

Smith, E. D. 2001. "Texts and the Ontology of Organizations and Institutions." Studies in Cultures, Organizations and Societies 7 (2): 159-198.

Strati, A. 1997. "Organization as Hypertext: A Metaphor from Visual Cultures." Studies in Cultures, Organizations and Societies 3 (2): 307-324.

Tillich, P. 1956. Dynamics of Faith. New York, NY: Harper and Brothers.

Tsoukas, H., and R. Chia. 2002. "On Organizational Becoming: Rethinking Organizational Change." Organization Science 13 (5): 567-582.

Weick, K. E. 1979. The Social Psychology of Organizing. New York: Random House.

Weick, K. E. 1995. Sensemaking in Organizations. Thousand Oaks, CA: Sage.

Weick, K. E. 2003. "Positive Organizing and Organizational Tragedy." In Positive Organizational Scholarship: Foundations of a New Discipline, edited by K. S. Cameron, J. E. Dutton, and R. E. Quinn, 66-80. San Francisco, CA: Berrett-Koehler.

Weick, E. 2011. "In Deep Waters: Process Theory Between Scylla and Charybdis." Organization 18 (5): 655-672.

Weick, K. E., and K. M. Sutcliffe. 2001. Managing the Unexpected: Assuring High Performance in an Age of Complexity. San Francisco, CA: Jossey-Bass.

Willmott, H. C. 1997. "Management and Organization Studies as Science? Methodologies of OR in Critical Perspective." Organization 4 (3): 309-344. 